Marquette University

e-Publications@Marquette

\title{
A Transdiagnostic Perspective of Constructs Underlying Obsessive-Compulsive and Related Disorders: An International Delphi Consensus Study
}

\author{
Leonardo F. Fontenelle \\ Monash University \\ Erin Oldenhof \\ Monash University \\ Maria Eduarda Moreira-de-Oliveira \\ Federal University of Rio de Janeiro \\ Jonathan S. Abramowitz \\ University of North Carolina at Chapel Hill \\ Martin M. Antony \\ Rglessthionaredsatdditional works at: https://epublications.marquette.edu/psych_fac \\ Part of the Psychology Commons
}

See nexi page for acaiaitional auiniors

Recommended Citation

Fontenelle, Leonardo F.; Oldenhof, Erin; Moreira-de-Oliveira, Maria Eduarda; Abramowitz, Jonathan S.; Antony, Martin M.; Cath, Danielle; Carter, Adrian; Dougherty, Darin D.; Ferrao, Ygor A.; Figee, Martijn; Harrison, Ben J.; Hoexter, Marcelo; Kwon, Jun Soo; Küelz, Anne; Lazaro, Luisa; Lochner, Christine; Marazziti, Donatella; Mataix-Cols, David; McKay, Dean; Miguel, Euripedes C.; Morein-Zamir, Sharon; Mortiz, Steffen; Nestadt, Gerald; O'Connor, Kieron; Pallanti, Stefano; Purdon, Christine; Rauch, Scott; Richter, Peggy; Rotge, Jean-Yves; Shavitt, Roseli G.; Soriano-Mas, Carles; Starcevic, Vladan; Stein, Dan J.; Steketee, Gail; Storch, Eric A.; Taylor, Steven; van den Heuvel, Odile A.; Veale, David; Woods, Douglas W.; VerdejoGarcia, Antonio; and Yucel, Murat, "A Transdiagnostic Perspective of Constructs Underlying ObsessiveCompulsive and Related Disorders: An International Delphi Consensus Study" (2020). Psychology Faculty Research and Publications. 512.

https://epublications.marquette.edu/psych_fac/512 


\section{Authors}

Leonardo F. Fontenelle, Erin Oldenhof, Maria Eduarda Moreira-de-Oliveira, Jonathan S. Abramowitz, Martin M. Antony, Danielle Cath, Adrian Carter, Darin D. Dougherty, Ygor A. Ferrao, Martijn Figee, Ben J. Harrison, Marcelo Hoexter, Jun Soo Kwon, Anne Küelz, Luisa Lazaro, Christine Lochner, Donatella Marazziti, David Mataix-Cols, Dean McKay, Euripedes C. Miguel, Sharon Morein-Zamir, Steffen Mortiz, Gerald Nestadt, Kieron O'Connor, Stefano Pallanti, Christine Purdon, Scott Rauch, Peggy Richter, Jean-Yves Rotge, Roseli G. Shavitt, Carles Soriano-Mas, Vladan Starcevic, Dan J. Stein, Gail Steketee, Eric A. Storch, Steven Taylor, Odile A. van den Heuvel, David Veale, Douglas W. Woods, Antonio Verdejo-Garcia, and Murat Yucel 
Marquette University

e-Publications@Marquette

\section{Psychology Faculty Research and Publications/College of Arts and Sciences}

This paper is NOT THE PUBLISHED VERSION.

Access the published version via the link in the citation below.

Australian \& New Zealand Journal of Psychiatry, Vol. 54, No. 7 (July 2020): 719-731. DOI. This article is (C) SAGE Publications and permission has been granted for this version to appear in $\underline{\mathrm{e}-}$

Publications@Marquette. SAGE Publications does not grant permission for this article to be further copied/distributed or hosted elsewhere without express permission from SAGE Publications.

\section{A Transdiagnostic Perspective of Constructs Underlying Obsessive-Compulsive and Related Disorders: An International Delphi Consensus Study}

Leonardo F. Fontenelle

Turner Institute for Brain and Mental Health, School of Psychological Sciences, Monash University, Melbourne, VIC, Australia

D’Or Institute for Research and Education, D’Or São Luiz Network, Rio de Janeiro, Brazil

Obsessive, Compulsive, and Anxiety Spectrum Research Program, Institute of Psychiatry, Federal University of Rio de Janeiro, Rio de Janeiro, Brazil

Erin Oldenhof

Turner Institute for Brain and Mental Health, School of Psychological Sciences, Monash University, Melbourne, VIC, Australia

Maria Eduarda Moreira-de-Oliveira

D’Or Institute for Research and Education, D’Or São Luiz Network, Rio de Janeiro, Brazil

Obsessive, Compulsive, and Anxiety Spectrum Research Program, Institute of Psychiatry, Federal University of Rio de Janeiro, Rio de Janeiro, Brazil 


\section{Jonathan S. Abramowitz}

Department of Psychology and Neuroscience, The University of North Carolina at Chapel Hill, Chapel Hill, NC

\section{Martin M. Antony}

Department of Psychology, Ryerson University, Toronto, ON, Canada

Danielle Cath

RGOc and Department of Psychiatry, Rijksuniversity Groningen, UMC Groningen, Groningen, The Netherlands

Department of Specialized Trainings, Mental Health Services Drenthe, Assen, The Netherlands

\section{Adrian Carter}

Turner Institute for Brain and Mental Health, School of Psychological Sciences, Monash University, Melbourne, VIC, Australia

Darin Dougherty

Division of Neurotherapeutics, Massachusetts General Hospital, Boston, MA

Obsessive-Compulsive Disorder Institute, McLean Hospital, Belmont, MA

Obsessive-Compulsive and Related Disorders Program, Massachusetts General Hospital, Boston, MA Department of Psychiatry, Harvard Medical School, Boston, MA

\section{Ygor A Ferrão}

Department of Psychiatry, Federal University of Health Sciences of Porto Alegre (UFCSPA), Porto Alegre, Brazil

\section{Martijn Figee}

Department of Psychiatry, Amsterdam University Medical Center, University of Amsterdam, Amsterdam, The Netherlands

Department of Psychiatry, Icahn School of Medicine at Mount Sinai, New York City, NY

\section{Ben J. Harrison}

Melbourne Neuropsychiatry Centre, Department of Psychiatry, The University of Melbourne, Melbourne, VIC, Australia

\section{Marcelo Hoexter}

Department of Psychiatry, Faculdade de Medicina, Universidade de São Paulo, São Paulo, Brazil

\section{Jun Soo Kwon}

Department of Psychiatry, College of Medicine, Seoul National University, Seoul, Korea

\section{Anne Küelz}

Department of Psychiatry and Psychotherapy, Medical Center, Faculty of Medicine, University of Freiburg, Freiburg, Germany

\section{Luísa Lazaro}

Department of Child and Adolescent Psychiatry and Psychology, Hospital Clinic of Barcelona, IDIBAPS, CIBERSAM, University of Barcelona, Barcelona, Spain

\section{Christine Lochner}

SU/UCT MRC Unit on Risk and Resilience in Mental Disorders, Department of Psychiatry, Stellenbosch University, Stellenbosch, South Africa

Donatella Marazziti

Dipartimento di Medicina Clinica e Sperimentale, Section of Psychiatry, University of Pisa, Pisa, Italy 


\section{David Mataix-Cols}

Department of Clinical Neuroscience, Karolinska Institutet, Stockholm, Sweden

Dean McKay

Department of Psychology, Fordham University, Bronx, NY

Euripedes C. Miguel

Department of Psychiatry, Faculdade de Medicina, Universidade de São Paulo, São Paulo, Brazil

Sharon Morein-Zamir

School of Psychology and Sports Science, Anglia Ruskin University, Cambridge, UK

\section{Steffen Moritz}

Department of Psychiatry and Psychotherapy, University Medical Center Hamburg-Eppendorf, Hamburg, Germany

\section{Gerald Nestadt}

Department of Psychiatry and Behavioral Sciences, School of Medicine, Johns Hopkins University, Baltimore, MD

\section{Kieron O'Connor}

Research Center of the Montreal University Institute of Mental Health, University of Montreal, Montreal, QC, Canada

Stefano Pallanti

Department of Psychiatry and Behavioral Sciences, Stanford University Medical Center, Stanford, CA Institute of Neuroscience, University of Florence, Florence, Italy

\section{Christine Purdon}

Department of Psychology, University of Waterloo, Waterloo, ON, Canada

\section{Scott Rauch}

Obsessive-Compulsive Disorder Institute, McLean Hospital, Belmont, MA

Department of Psychiatry, Harvard Medical School, Boston, MA

\section{Peggy Richter}

Anxiety Disorders Centre, Sunnybrook Health Care Sciences, Toronto, Canada and Department of Psychiatry, University of Toronto, Toronto, Canada

\section{Jean-Yves Rotge}

Inserm U 1127, CNRS UMR 7225, Department of Psychiatry, Institut du Cerveau et de la Moelle, ICM-AIHU, Sorbonne Université, AP-HP, Paris, France

\section{Roseli G. Shavitt}

Department of Psychiatry, Faculdade de Medicina, Universidade de São Paulo, São Paulo, Brazil

\section{Carles Soriano-Mas}

Department of Psychiatry and Department of Psychobiology and Methodology of Health Sciences, Bellvitge Biomedical Research Institute-IDIBELL, Mental Health Networking Biomedical Research Centre (CIBERSAM) and Universitat Autònoma de Barcelona, Barcelona, Spain

\section{Vladan Starcevic}

Department of Psychiatry, Nepean Hospital, Faculty of Medicine and Health, Sydney Medical School, Nepean Clinical School, The University of Sydney, Sydney, NSW, Australia

\section{Dan J. Stein}


Department of Psychiatry and MRC Unit on Risk \& Resilience in Mental Disorders, University of Cape Town, Cape Town, South Africa

\section{Gail Steketee}

School of Social Work, Boston University, Boston, MA

\section{Eric A Storch}

Menninger Department of Psychiatry and Behavioral Sciences, Baylor College of Medicine, Houston, TC

\section{Steven Taylor}

Department of Psychiatry, The University of British Columbia, Vancouver, BC, Canada

\section{Odile A. van den Heuvel}

Department of Psychiatry and Department of Anatomy \& Neurosciences, Amsterdam Neuroscience, Amsterdam UMC, Vrije Universiteit, Amsterdam, The Netherlands

Bergen Center for Brain Plasticity, Haukeland University Hospital, Bergen, Norway

David Veale

South London and Maudsley NHS Foundation Trust, Institute of Psychiatry, Psychology and Neuroscience, King's College London, London, UK

\section{Douglas W. Woods}

Department of Psychological and Brain Sciences, Texas A\&M University, College Station, TX Department of Psychology, Marquette University, Milwaukee, WI

\section{Antonio Verdejo-Garcia}

Turner Institute for Brain and Mental Health, School of Psychological Sciences, Monash University, Melbourne, VIC, Australia

\section{Murat Yücel}

Turner Institute for Brain and Mental Health, School of Psychological Sciences, Monash University, Melbourne, VIC, Australia

\section{The International OCRDs Neuroscience Consensus Group}

\section{Abstract}

\section{Background:}

The Research Domain Criteria seeks to bridge knowledge from neuroscience with clinical practice by promoting research into valid neurocognitive phenotypes and dimensions, irrespective of symptoms and diagnoses as currently conceptualized. While the Research Domain Criteria offers a vision of future research and practice, its 39 functional constructs need refinement to better target new phenotyping efforts. This study aimed to determine which Research Domain Criteria constructs are most relevant to understanding obsessive-compulsive and related disorders, based on a consensus between experts in the field of obsessive-compulsive and related disorders.

\section{Methods:}

Based on a modified Delphi method, 46 experts were recruited from Australia, Africa, Asia, Europe and the Americas. Over three rounds, experts had the opportunity to review their opinion in light of feedback from the previous round, which included how their response compared to other experts and a summary of comments given. 


\section{Results:}

Thirty-four experts completed round one, of whom 28 (82\%) completed round two and 24 (71\%) completed round three. At the final round, four constructs were endorsed by $\geqslant 75 \%$ of experts as 'primary constructs' and therefore central to understanding obsessive-compulsive and related disorders. Of these constructs, one came from the Positive Valence System (Habit), two from the Cognitive Control System (Response Selection/Inhibition and Performance Monitoring) and the final construct was an additional item suggested by experts (Compulsivity).

\section{Conclusion:}

This study identified four Research Domain Criteria constructs that, according to experts, cut across different obsessive-compulsive and related disorders. These constructs represent key areas for future investigation, and may have potential implications for clinical practice in terms of diagnostic processes and therapeutic management of obsessive-compulsive and related disorders.

\section{Keywords}

Obsessive-compulsive and related disorders, Research Domain Criteria, habit, cognitive control, compulsivity

\section{Introduction}

In its latest edition, the Diagnostic and Statistical Manual of Mental Disorders (5th ed.; DSM-5)

introduced a novel category titled obsessive-compulsive and related disorders (OCRDs), which includes obsessive-compulsive disorder (OCD), body dysmorphic disorder (BDD), hoarding disorder, trichotillomania (TTM; hair pulling disorder), and excoriation (skin-picking) disorder (APA, 2013). The current revision of the International Classification of Diseases and Related Health Problems (ICD-11) also added olfactory reference disorder (ORD) and hypochondriasis to OCRDs (Stein et al., 2016). The creation of the OCRDs chapter was based on initial evidence suggesting that its disorders relate to one another on a range of 'diagnostic validators' (APA, 2013), including symptom presentation, neurobiological correlates (e.g. striatal dysfunction), patterns of comorbidity and familiality (Fineberg et al., 2010). However, there is presently no clear consensus on the behavioral/cognitive dysfunctions shared by all OCRDs, which remain largely elusive (Fineberg et al., 2010).

The difficulty in identifying a common cognitive signature for all OCRDs lies in the characterization of the dysfunctional systems involved in the pathophysiology of OCD itself, the paradigmatic OCRD around which all other OCRDs appear to orbit. The neurocognitive underpinnings of OCD have been suggested to involve different degrees of impairment across a range of areas, including executive function (response inhibition, planning, set-shifting and fluency), processing speed, attention, memory and visual spatial abilities (Abramovitch and Cooperman, 2015). What is unclear is whether these areas of dysfunction are shared by most OCRDs, and consequently differentiates OCRDs as a distinct group from other mental disorders. It is also unknown whether these systems characterize a particular stage of illness within OCRDs, or if they represent OCRD endophenotypes. Generally, endophenotypes are defined as highly heritable, state independent traits that co-segregate with illnesses within families and occur also in non-affected family members (Gottesman and Gould, 2003). 
It is beyond the scope of this paper to review all studies of putative endophenotypes in OCD, but a range of candidates within the cognitive systems have been identified, including increased errorrelated brain potentials (Riesel, 2019), lateral orbitofrontal cortex hypoactivation during reversal learning (Chamberlain et al., 2008), presupplementary motor area hyperactivity during response inhibition (De Wit et al., 2012), compensatory fronto-parietal activity during working memory (De Vries et al., 2014) and hypoactivation of cortical regions associated with goal-directed planning and frontostriatal dysconnectivity (Vaghi et al., 2017). In addition, functional abnormalities within the cortico-striato-thalamo-cortical (CSTC), fronto-limbic and fronto-parietal circuits have also been reported as potential endophenotypes (Shaw et al., 2015). However, similarly to the neuropsychological literature reviewed above (Abramovitch and Cooperman, 2015), it is unclear whether these findings generalize to other OCRDs or should be limited to OCD specifically.

The Research Domain Criteria (RDoC) is an initiative of the National Institute of Mental Health (NIMH) that aims to understand psychiatric phenomena from a dimensional standpoint, in contrast to the prevailing disorder-based systems of the DSM or ICD. As such, the RDoC may provide a valuable framework through which to identify traits shared by all OCRDs (Brooks et al., 2017). The RDoC lists several 'candidate' psychological constructs (or concepts) and their corresponding 'units of analysis' (genes, molecules, neurocircuits, etc.) that seek to link behaviors and mental acts to specific brain systems. While links between some psychiatric phenotypes (e.g. DSM-5 anxiety disorders) and RDoC constructs (e.g. acute or potential threat) seem intuitive, the relationships between specific OCRDs and such constructs are less obvious as OCRDs can be quite clinically (and therapeutically) heterogeneous.

In research, when there is a need to converge opinions about a particular topic that cannot easily be addressed with traditional methods, consensus approaches are frequently adopted (Jorm, 2015). Correspondingly, this approach offers the opportunity to determine which RDoC constructs are considered transdiagnostic and cut across the range of OCRDs. The Delphi Technique is a consensus method often used in mental health research, and is employed to achieve the most reliable agreement between a group of experts on a given topic. Using multiple stages to canvas expert opinion, the Delphi Technique has helped psychiatry to form predictions, priorities and foundational concepts when current evidence is incomplete (Jorm, 2015). A recent example saw the empirical definition of treatment response, remission, recovery and relapse for clinical trials of OCD (Mataix-Cols et al., 2016). The present study used a modified Delphi method to determine which RDoC constructs were perceived by experts as most important to understanding OCRDs. A secondary aim was to characterize constructs in relation to the stage of illness (i.e. vulnerability or maintenance/chronicity) to offer a more detailed understanding of their transdiagnostic function.

\section{Methods and materials}

\section{Expert panel}

Experts were recruited through purposive sampling, where selection was based on being known to the members of the research group (L.F. and M.Y.) as having relevant clinical or research experience in OCRDs or being world-renowned experts (e.g. members of editorial boards of specialized journals such as the Journal of Obsessive-Compulsive and Related Disorders). In addition, experts were required to have a minimum of 5 years of experience in their profession, authored more than 50 peer-reviewed 
journal articles and speak English fluently. As outlined by Okoli and Pawlowski (2004), a list of potential experts was generated and then categorized (according to field of expertise, profession, number of publications, country and organizations), ranked and prioritized and then sent invitations based on a minimum sample size of 20 (Akins et al., 2005). In total, 71 email invitations were sent, 46 experts consented, and 34 participated in the study. These experts were recruited from Africa $(n=2)$, Asia $(n=1)$, Australia $(n=2)$, Europe $(n=12)$ and North and South America ( $n=12$ and $n=5$, respectively). The local (Monash University) Human Research and Ethics Committee approved the study (CF15/34072015001454).

\section{Procedure}

The research methodology employed in the current study was similar to the one used in our previous Delphi study on addiction (Yucel et al., 2019). Although Delphi studies typically commence in an open format, the present study employed a modified Delphi method where the 39 RDoC constructs (see Figure 1) formed the basis of the first-round questionnaire. In knowing that the RDoC is proposed as a starting point for research rather than a complete guide, experts were also invited to propose additional constructs they considered important to understanding OCRDs. Under a structured group process, experts anonymously rated the relevancy of each construct to OCRDs. Once each round was complete, constructs not achieving consensus were carried forward into subsequent rounds for experts to re-rate. These constructs were presented with feedback from previous round responses, including the range and frequency of expert endorsements, the expert's own previous response and a synopsis of the groups' comments. Providing this summary of comments is thought to lead to a more accurate consensus, as opinions are unlikely to change without strong causal reasoning (Bolger and Wright, 2011). The three Delphi rounds were conducted between March 2016 and November 2017.
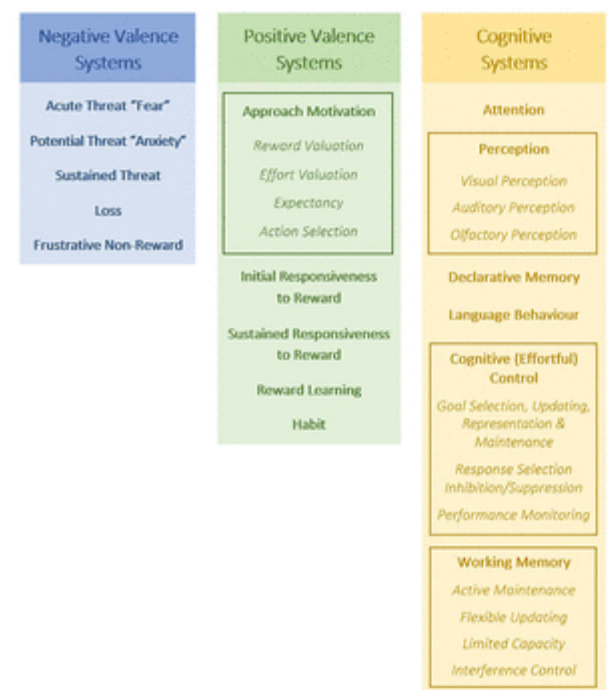
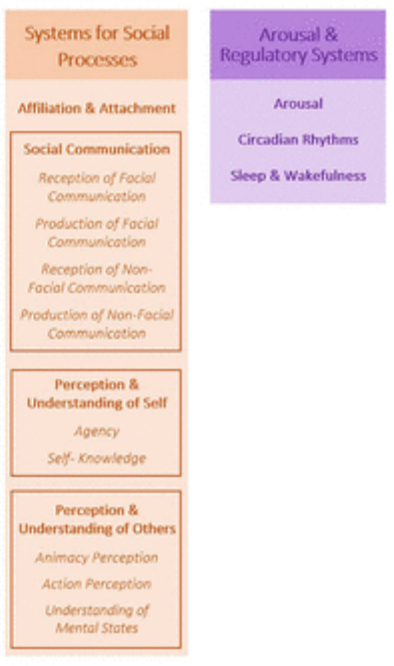

Figure 1. Overview of $39 \mathrm{RDoC}$ constructs highlighting the 5 major domains, comprising 23 main constructs (bolded text), wherein 7 of them (boxed sections) are subdivided into 23 sub-constructs (italicized text). Note that in June 2018 (after this study was completed), the Positive Valence domain of the RDoC matrix was restructured. Although the original constructs used in this study are mostly retained, they underwent a reorganization (see www.nimh.nih.gov/about/advisoryboards-and-groups/namhc/reports/rdocchanges-to-the-matrix-cmat-workgroup-update-proposedpositive-valence-domain-revisions.shtml). 
To maintain the rigor of the technique and preserve an acceptable response rate of at least $70 \%$ across rounds (Sumsion, 1998), identifiable data were disclosed to key researchers to follow up with nonresponders, which occurred up to three times each round. In the third and final round, experts who remained outside of the consensus range were required to explain their rating in order to clarify their judgments.

\section{Data analyses}

\section{Defining consensus}

A 5-point Likert-type scale ranging from 1 (Unimportant) to 5 (Essential) was used, with a non-neutral midpoint of 3 (Moderately Important) to force experts to deliberate and form an opinion. Where experts did not have the knowledge to do so, an 'Unsure/Don't Know' option was available as an addendum. Consensus was defined as $\geqslant 75 \%$ experts endorsing a construct within two scale points (Diamond et al., 2014); constructs were excluded from the study if consensus arose among the lowest three scale points ('Unimportant' to 'Moderately Important') and included if they achieved consensus between the top two scale points ('Very Important' and 'Essential').

Conclusion of the Delphi was not solely reliant on achieving consensus, but also on the stability of experts' responses (Guzys et al., 2015), which allows disagreement to be preserved. The Delphi process was therefore deemed complete when either all items had achieved consensus or when movement between rounds was less than $15 \%$, indicating that opinions were not likely to be affected further (Linstone and Turoff, 1975).

\section{Quantitative analyses}

SPSS (v.22) (IBM Corporation, 2013) was used for data cleaning and all quantitative analyses.

Frequencies were calculated to assess consensus. To assess stability over rounds, percentage of change was calculated to indicate the number of experts who changed their response between rounds in relation to the group, reflecting the percentage of experts modifying their response each round (Scheibe et al., 1975).

\section{Qualitative analyses}

In order to systematically process the qualitative data, thematic analysis was carried out according to guidelines set out by Braun and Clarke (2006). First, comments were coded in relation to level of importance (i.e. unimportant to essential), and relevance for staging (i.e. whether constructs were related to vulnerability or chronicity of OCRDs). The resulting matrix was then grouped into themes, and within these, comments were summarized and reduced to eliminate repetition. The summarization involved selection of more informative, rational or well-explained comments in order to retain as much of the experts original wording as possible (Hasson et al., 2000). Repetitive comments were removed in order to decrease the risk of same-thinking, which can lead to an increased confidence in ones' own opinion, and all variety of responses was included in order to challenge conventional thinking (Bolger and Wright, 2011).

As suggested by Jorm (2015), the additional constructs recommended by experts were evaluated by a small consensus team (E.O., L.F. and M.Y.) to confirm that they were (1) not already covered by the survey (i.e. the RDoC Matrix); (2) within the scope of the study; and (3) articulated clearly-if they were not, the research group went on to review and adjust the description accordingly. For example, when 
an expert gave the name of a construct but no definition, or where the description was to brief to clearly understand the proposed construct, the research group developed or built on this definition based on the literature. These additional constructs were then added to subsequent versions of the survey.

\section{Results}

\section{Retention and characteristics of experts}

Assuring a transdiagnostic approach experts were representative of the different OCRDs (OCD, BDD, hoarding disorder, TTM and skin-picking). Of the 34 experts that completed round one of the Delphi questionnaires, 28 (82.3\%) went on to complete round two and $24(71 \%)$ completed round three, remaining within the acceptable retention rate. Experts who completed round one were aged 3766 years $(M=50.1$, standard deviation $[S D]=7.9)$, with $67.6 \%(N=23)$ being males. The experts were mostly psychiatrists (55.9\%), scientists/neuroscientists (50.0\%) and psychologists/neuropsychologists (38.2\%). Their professional settings were primarily universities (85.3\%), hospitals (44.1\%), private practice (17.6\%) and outpatient clinics (14.7\%). The most commonly held academic titles were Professor (55.9\%), Associate Professor (32.4\%) and Research Fellow/Senior Lecturers (14.7\%), with the majority of experts holding a PhD (89\%).

\section{Expert consensus on functional domains}

Overall, the consensus supported the inclusion of four items as primary constructs, namely: (1) Habit, (2) Response Selection/Inhibition, (3) Performance Monitoring and (4) Compulsivity (see Figure 2 for flow chart; Figure 3 for an overview of the final consensus for all constructs and Table 1 for definitions). 
Table 1. RDoC definitions of the four primary domains, together with the relevant circuitry, self-report and neurocognitive testing paradigms.

\begin{tabular}{|c|c|c|c|c|c|c|}
\hline Construct & Definition & Circuits & Physiology/behavior & Self-report & Paradigms & $\begin{array}{l}\text { Expert } \\
\text { commentary } \\
\text { (selective) }\end{array}$ \\
\hline Habit & $\begin{array}{l}\text { Sequential, } \\
\text { repetitive, motor } \\
\text { or cognitive } \\
\text { behaviors elicited } \\
\text { by external or } \\
\text { internal triggers } \\
\text { that, once initiated, } \\
\text { can go to } \\
\text { completion } \\
\text { without constant } \\
\text { conscious } \\
\text { oversight. Habits } \\
\text { can be adaptive by } \\
\text { virtue of freeing up } \\
\text { cognitive } \\
\text { resources. Habit } \\
\text { formation is a } \\
\text { frequent } \\
\text { consequence of } \\
\text { reward learning, } \\
\text { but its expression } \\
\text { can become } \\
\text { resistant to } \\
\text { changes in } \\
\text { outcome value. } \\
\text { Related behaviors } \\
\text { could be } \\
\text { pathological } \\
\text { expression of a } \\
\text { process that under } \\
\text { normal } \\
\text { circumstances } \\
\text { subserves adaptive } \\
\text { goals. }\end{array}$ & $\begin{array}{l}\text { Dorsal striatum } \\
\text { Medial prefrontal } \\
\text { SN/VTA Ventral } \\
\text { striatum }\end{array}$ & $\begin{array}{l}\text { Compulsive behaviors } \\
\text { Repetitive behaviors } \\
\text { Stereotypic behaviors }\end{array}$ & $\begin{array}{l}\text { Aberrant behaviors } \\
\text { checklist Measures } \\
\text { of repetitive } \\
\text { behaviors }\end{array}$ & $\begin{array}{l}\text { Devaluation task Habit } \\
\text { Learning Task Habit Task }\end{array}$ & $\begin{array}{l}\text { 'Particularly } \\
\text { relevant for } \\
\text { checkers' }\end{array}$ \\
\hline
\end{tabular}




\begin{tabular}{|c|c|c|c|c|c|c|}
\hline $\begin{array}{l}\text { Response Selection } \\
\text { Inhibition/Suppression }\end{array}$ & $\begin{array}{l}\text { A sub-construct of } \\
\text { the cognitive } \\
\text { control system that } \\
\text { is responsible for } \\
\text { operation of } \\
\text { cognitive and } \\
\text { emotional systems, } \\
\text { in the service of } \\
\text { goal-directed } \\
\text { behavior. This } \\
\text { function is required } \\
\text { when prepotent } \\
\text { responses (those } \\
\text { automatically } \\
\text { elicited) are not } \\
\text { adequate to meet } \\
\text { the demands of the } \\
\text { current context or } \\
\text { need to be } \\
\text { suppressed. } \\
\text { Response } \\
\text { inhibition has been } \\
\text { presented in the } \\
\text { literature as a facet } \\
\text { of response } \\
\text { selection, an } \\
\text { executive process } \\
\text { where one } \\
\text { consciously } \\
\text { withholds a } \\
\text { response in the } \\
\text { service of goal- } \\
\text { directed behavior }\end{array}$ & $\begin{array}{l}\text { DLPFC PPC VLPFC } \\
\text { BA6/8(FEF) Pre-SMA } \\
\text { PPC } \\
\text { Ventrofrontostriatal }\end{array}$ & $\begin{array}{l}\text { Gamma Theta } \\
\text { Impulsive behaviors } \\
\text { Alpha Pupilometry } \\
\text { Short interval cortical } \\
\text { inhibition (TMS) } \\
\text { Impulsive behaviors } \\
\text { Distractibility Off-task } \\
\text { behaviors }\end{array}$ & $\begin{array}{l}\text { BRIEF (Gioa) } \\
\text { SANS/SAPS/PANSS } \\
\text { ADHD Rating Scale } \\
\text { (DuPaul) ATQ/CBQ } \\
\text { Effortful Control } \\
\text { BRIEF (Gioa) } \\
\text { Conners impulsivity } \\
\text { scale }\end{array}$ & $\begin{array}{l}\text { Flanker, Simon, Stroop } \\
\text { Antisaccade } \\
\text { Conflicting/contralateral } \\
\text { motor response task } \\
\text { Countermanding } \\
\text { Go/Nogo Motor } \\
\text { persistence paradigms } \\
\text { Stimulus- } \\
\text { Response Incompatibility } \\
\text { Stop-Signal Reaction Time }\end{array}$ & $\begin{array}{l}\text { 'This is an area } \\
\text { where some } \\
\text { tasks (i.e. } \\
\text { go/nogo) show } \\
\text { robust } \\
\text { associations- } \\
\text { but the } \\
\text { mechanisms by } \\
\text { which this } \\
\text { influences OCD } \\
\text { is unclear' } \\
\text { 'Difficulty in } \\
\text { inhibiting } \\
\text { responses, } \\
\text { especially in } \\
\text { STOP } \\
\text { paradigms' 'Here } \\
\text { we find core } \\
\text { deficits in OCD' } \\
\text { 'Evidence of } \\
\text { inhibitory } \\
\text { deficits' }\end{array}$ \\
\hline $\begin{array}{l}\text { Performance } \\
\text { Monitoring }\end{array}$ & $\begin{array}{l}\text { A sub-construct of } \\
\text { the cognitive } \\
\text { control system, } \\
\text { responsible for } \\
\text { modulating other } \\
\text { cognitive and } \\
\text { emotional systems, } \\
\text { in the service of }\end{array}$ & ACC/pre-SMA Insula & $\begin{array}{l}\text { ERN N2 N450 Post- } \\
\text { error or post-conflict } \\
\text { adjustments in } \\
\text { performance }\end{array}$ & YBOCS total score & Flanker, Simon, Stroop & $\begin{array}{l}\text { 'Over vigilance } \\
\text { to sensations } \\
\text { and thoughts' } \\
\text { 'Over monitoring } \\
\text { of thoughts and } \\
\text { sensations' }\end{array}$ \\
\hline
\end{tabular}




\begin{tabular}{|c|c|c|c|c|c|c|}
\hline & $\begin{array}{l}\text { goal-directed } \\
\text { behavior, when } \\
\text { prepotent modes } \\
\text { of responding are } \\
\text { not adequate to } \\
\text { meet the demands } \\
\text { of the current } \\
\text { context. } \\
\text { Additionally, } \\
\text { control processes } \\
\text { are engaged in the } \\
\text { case of novel } \\
\text { contexts, where } \\
\text { appropriate } \\
\text { responses need to } \\
\text { be selected from } \\
\text { among competing } \\
\text { alternatives and } \\
\text { allows feedback } \\
\text { learning where } \\
\text { behavior can be } \\
\text { adjusted in order } \\
\text { to optimize goal- } \\
\text { directed behavior. }\end{array}$ & & & & & \\
\hline Compulsivity & $\begin{array}{l}\text { This is the only } \\
\text { additional } \\
\text { construct to the } \\
\text { RDoC that went on } \\
\text { to receive } \\
\text { endorsement as } \\
\text { primary construct. } \\
\text { In the present } \\
\text { study, compulsivity } \\
\text { was defined as } \\
\text { being } \\
\text { goal-directed } \\
\text { behavior } \\
\text { associated with } \\
\text { negative outcome } \\
\text { expectancy that } \\
\text { contributes to the }\end{array}$ & $\begin{array}{l}\text { Dorsal } \\
\text { striatum VLPFC } \\
\text { DLPFC }\end{array}$ & $\begin{array}{l}\text { Difficulties resisting } \\
\text { urges and the } \\
\text { experience of loss of } \\
\text { voluntary control } \\
\text { Repetitive behaviors } \\
\text { performed in a } \\
\text { habitual or } \\
\text { stereotyped manner; } \\
\text { inappropriate } \\
\text { to the situation }\end{array}$ & $\begin{array}{l}\text { YBOCS } \\
\text { and related } \\
\text { instruments } \mathrm{FOCl} \\
\text { and related } \\
\text { instruments } \mathrm{OCl} \\
\text { and OCI-R } \\
\text { CHI-T }\end{array}$ & $\begin{array}{l}\text { IST } \\
\text { BART RL IDED } \\
\text { Fruit Task }\end{array}$ & $\begin{array}{l}\text { 'This construct } \\
\text { would appear to } \\
\text { fit across the } \\
\text { entire OCRD } \\
\text { spectrum' 'The } \\
\text { rapid } \\
\text { progression of } \\
\text { goal- directed } \\
\text { behavior into } \\
\text { habit behavior, } \\
\text { rather than goal- } \\
\text { directedness of } \\
\text { the behavior in } \\
\text { itself (possibly a } \\
\text { core } \\
\text { characteristic of } \\
\text { OCD)' }\end{array}$ \\
\hline
\end{tabular}




\begin{tabular}{|l|l|l|l|l|}
\hline & $\begin{array}{l}\text { experience of } \\
\text { being 'compelled' } \\
\text { to act. }\end{array}$ & & & \\
\hline
\end{tabular}

SN: substantia nigra; VTA: ventral tegmental area; DLPFC: dorso-lateral prefrontal cortex; PPC: posterior parietal cortex; VLPFC: ventro-lateral prefrontal cortex; BA: Brodmann's area; SMA: supplementary motor area; ACC: anterior cingulate cortex; TMS: transcranial magnetic stimulation; ERN: errorrelated negativity; N2 and N450: components of evoked potential (negative peaks); BRIEF: Behavior Rating Inventory of Executive Function; SANS: Scale for the Assessment of Negative Symptoms; SAPS: Scale for the Assessment of Positive Symptoms; PANSS: Positive and Negative Symptoms Scale; ADHD: attention-deficit/hyperactivity disorder; ATQ: Adult Temperament Questionnaire; CBQ: Children's Behavior Questionnaire; YBOCS: Yale-Brown Obsessive-Compulsive Scale; FOCI: Florida Obsessive-Compulsive Inventory; OCI: Obsessive-Compulsive Inventory; OCl-R: Obsessive-Compulsive Inventory-Revised; CHI-T: Cambridge-Chicago Compulsivity Trait; IST: information sampling task; BART: balloon analogue risk task; RL: reversal learning; IDED: intra-dimensional extra-dimensional. 


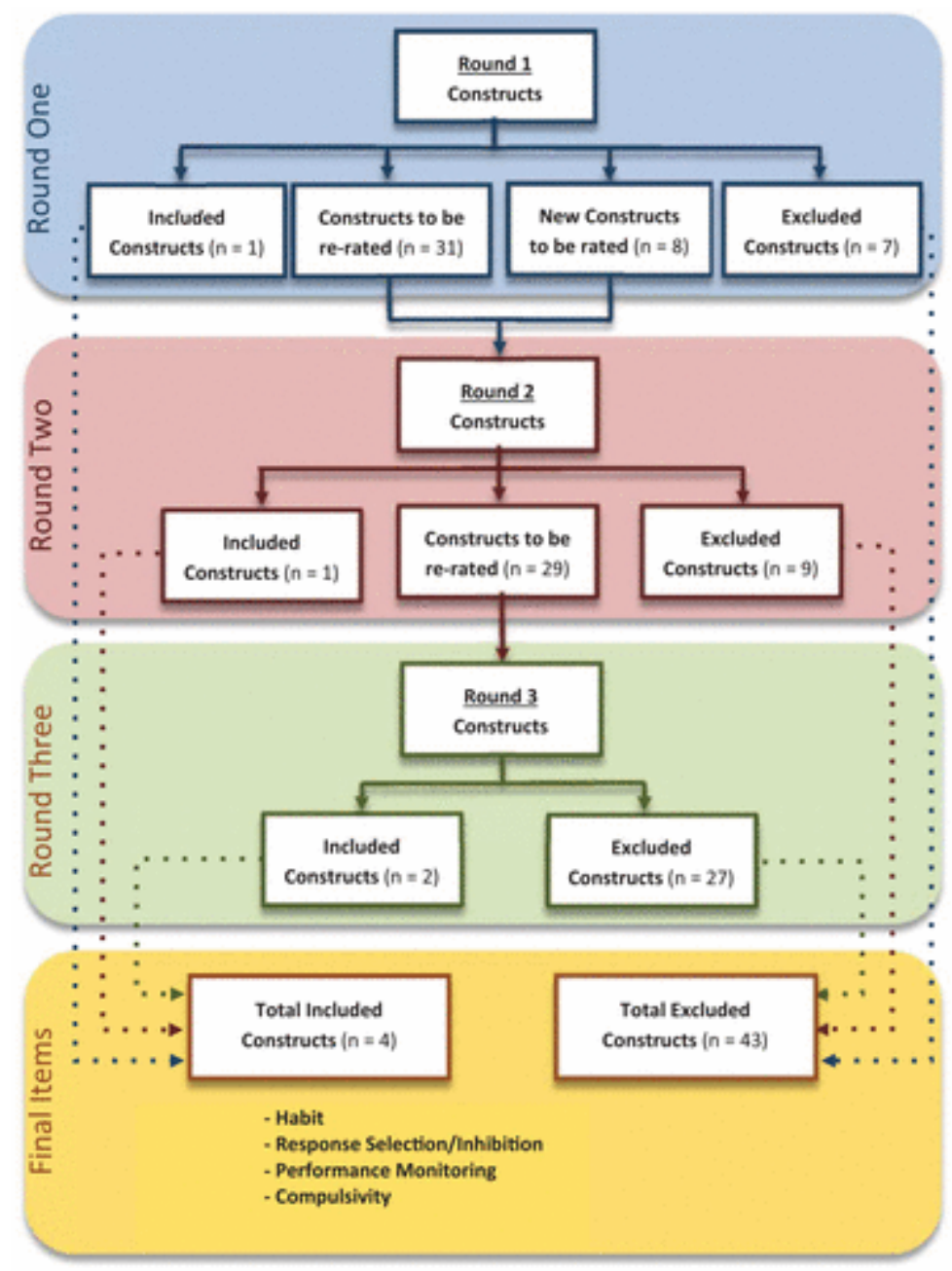

Figure 2. A flow chart displaying the movement of constructs over the rounds highlighting items that were endorsed by $\geqslant 75 \%$ of experts as being clearly relevant (i.e. primary constructs; included items), not relevant to OCRDs (excluded), created (i.e. new constructs recommended by experts) or re-rated over the three survey rounds. 


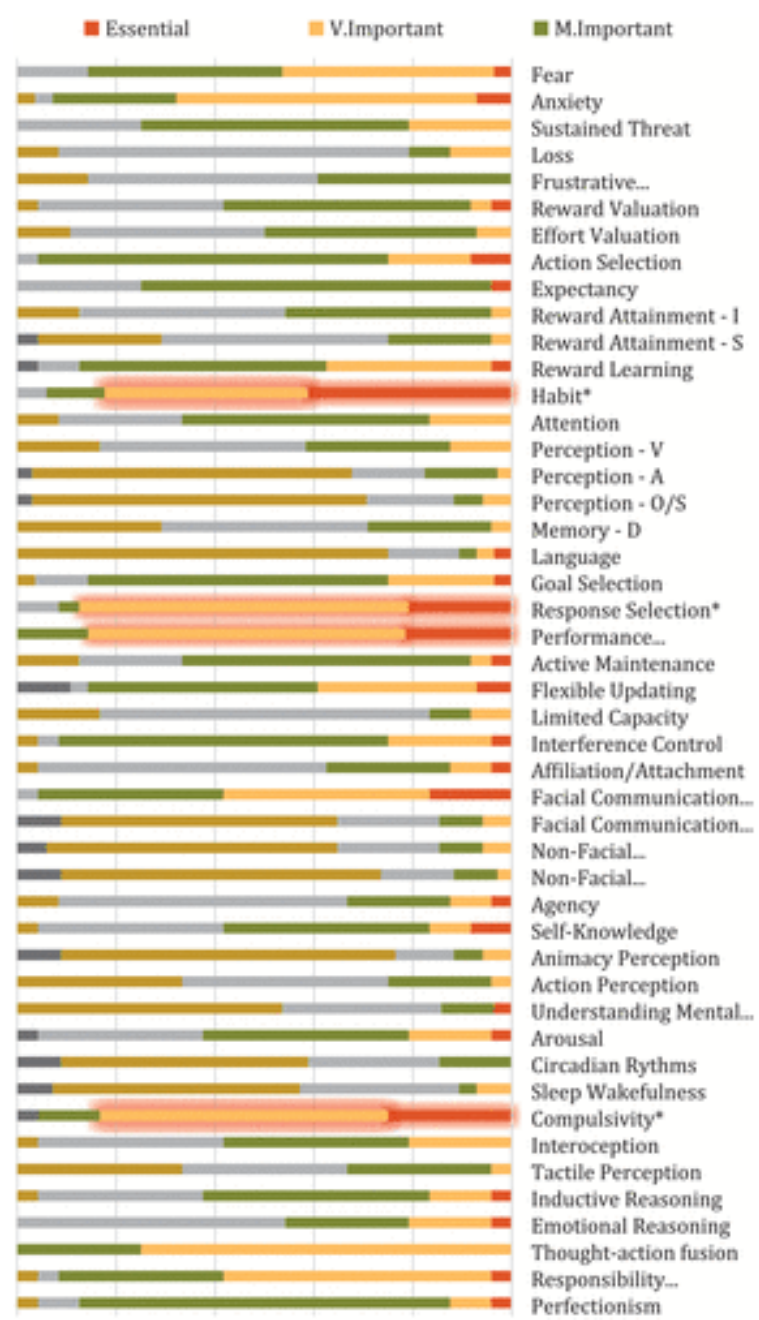

Figure 3. Overview of the final consensus level and range for all 39 RDoC constructs/sub-constructs and 8 additional constructs suggested by experts for inclusion. All constructs were investigated over three rounds.

Red highlight and asterisks indicate the constructs that were selected as 'Primary' across the three rounds. V. Important: very important; M. Important: moderately important; S. Important: somewhat important; I: initial; S: sustained; V: visual; A: auditory; O/S: olfactory/somatosensory; D: declarative; R: reception; P: production.

\section{Relevance of primary constructs to stage of illness}

Figure 4 shows that of the four primary constructs identified, 'Habit' was considered by the experts to be most relevant to chronicity to OCRDs (consensus rate of 94.2\%), followed by 'Response Selection and Inhibition/Suppression' and 'Performance Monitoring', both contributing equally for chronicity (consensus rate of 79\%) and 'Compulsivity' (68\%). There was no marked difference between chronicity and vulnerability to OCRDs. 


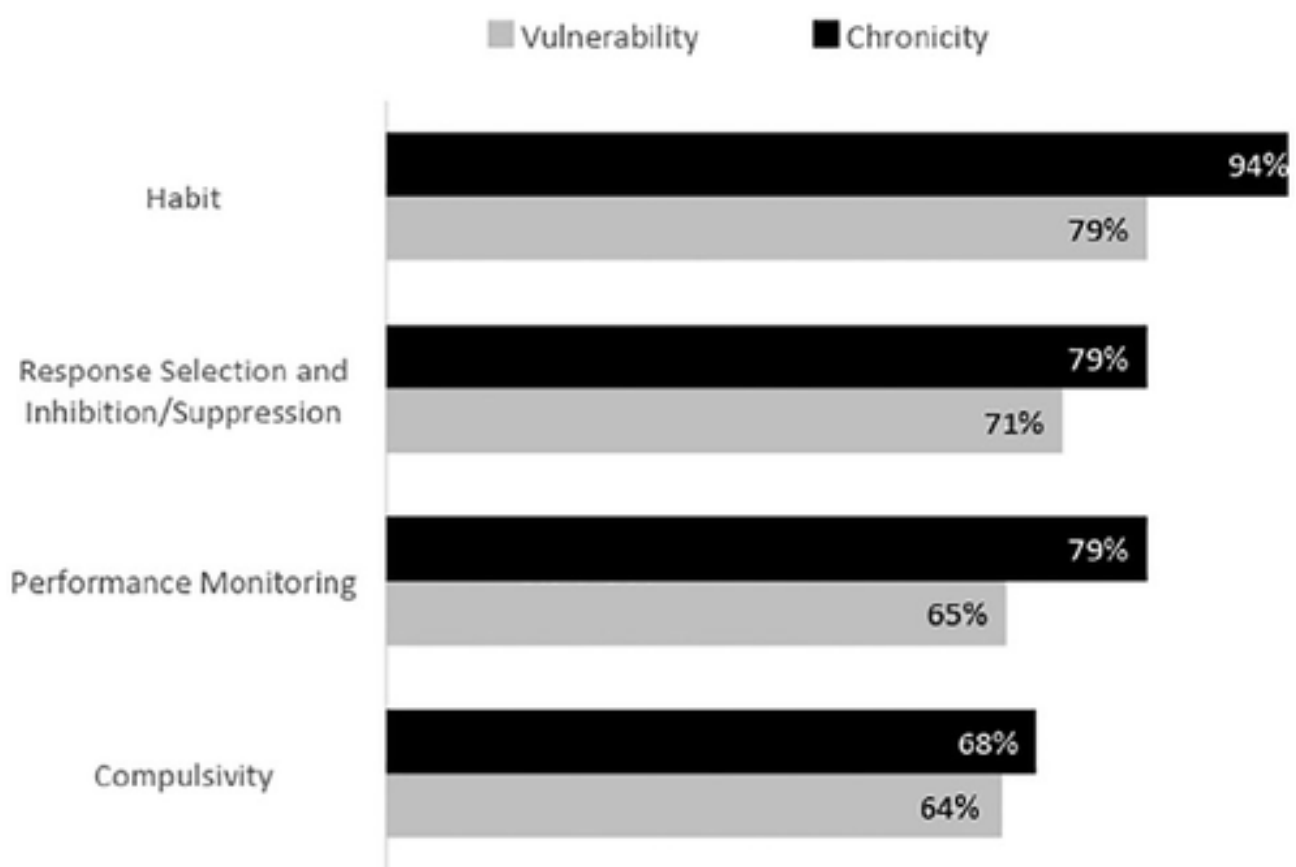

Figure 4. Experts' endorsements for stages of illness for primary constructs.

\section{Discussion}

The use of the Delphi methodology allowed experts in the field of OCRDs to reach a consensus on the core constructs central to a better understanding of these disorders. Three constructs from the RDoC matrix (response selection and inhibition/suppression, performance monitoring and habit) emerged as essential or very important to the pathophysiology of OCRDs according to the experts. A fourth construct (compulsivity), not originally listed in the RDoC matrix, was also identified as essential to the understanding of OCRDs. We also investigated if experts believed these constructs played different roles in the vulnerability to or chronicity of OCRDs. Accordingly, most of the primary constructs were endorsed by experts as contributing comparably to both stages of OCRDs, except for 'habit', which was considered marginally more relevant to chronicity (Figure 4).

The RDoC constructs believed to be relevant to the pathophysiology of OCRDs were subsumed by cognitive (cognitive control) and positive valence systems (habits). In contrast, no construct under negative valence systems (e.g. acute, potential or sustained threat, loss, or frustrative non-reward) was endorsed as being relevant for the pathophysiology of OCRDs as a group. These findings do not exclude, however, the critical role that these later systems might have in particular, rather than most OCRDs. For instance, OCD, whose 'compulsive behaviors' as described in DSM-5 (APA, 2013) are typically maintained by negative reinforcements (Andersen and Bech, 1981), are probably characterized by greater involvement of negative valence systems. However, whether central or just peripheral to the pathophysiology of specific OCRDs, cognitive and positive valence systems were judged to play a more universal role in the etiology of these conditions.

Cognitive control reflects a set of processes that serve goal-directed behavior by selecting goals, inhibiting responses and monitoring performance (NIMH, 2017). The perception by experts that impaired response selection inhibition/suppression characterizes OCRDs despite mixed evidence in the 
literature (Abramovitch and Cooperman, 2015), might have been influenced by impulsive-compulsive models (Fontenelle et al., 2011), which explain why compulsive and impulsive disorders/traits are commonly comorbid, both in clinical (Fontenelle et al., 2005) and in non-clinical (Cuzen et al., 2014) settings. Indeed, recent studies suggest that impulsive and compulsive traits share a common underlying psychopathological structure (Tiego et al., 2019). It seems justifiable, then, to pursue research on the links between OCRDs and, for instance, attention deficit hyperactivity disorder or disorders due to addictive behaviors, with potential implications for future classifications. Interestingly, impaired response inhibition/suppression and performance monitoring have been reported both in people with OCD and their unaffected first-degree family members, thus supporting their role as true OCD endophenotypes (Chamberlain et al., 2007).

On the other hand, while experts converged with the literature in agreeing that overactive performance monitoring is a core feature of OCD (Endrass and Ullsperger, 2014), they extended this feature to other OCRDs, for which no data currently exist. However, the placement of OCRDs directly after anxiety disorders in the DSM-5 was supported by the current study, given the fact that increased performance monitoring is evidenced across generalized anxiety disorder (Weinberg et al., 2015), separation anxiety disorder (Carrasco et al., 2013), social anxiety disorder (Riesel et al., 2014) and illness anxiety disorder (Riesel et al., 2017). It has also been suggested that increased doubt, a wellknown component of OCD (and probably of other anxiety disorders), is the most visible clinical manifestation of this enhanced error-monitoring phenotype (Pitman et al., 1987).

While several studies have suggested there is a propensity toward the formation of habits in OCD (e.g. Gillan et al., 2011), an online study found that deficits in goal-directed control were strongly associated with an extended phenotype comprising OCD and other 'non-official' OCRDs, such as addictions and eating disorders (Gillan et al., 2016). Clinically however, there is still debate on the overlaps between OCD and habits. For instance, whereas some OCD behaviors may be performed automatically, particularly in later stages of illness (Ferreira et al., 2017), it is intriguing that some OCD patients actually report being hyperaware of their rituals (Denys, 2011) and activate regions associated with explicit information processing (such as the medial temporal lobes bilaterally), during an implicit sequence-learning task (Rauch et al., 1997). Theoretically, involvement of habit systems may underlie not only the automaticity but also the increased inflexibility associated with compulsive behaviors (Smith and Graybiel, 2016).

Compulsivity is known to play a central role in the characterization of OCRDs (Marras et al., 2016), and previous studies have already suggested its adoption by the RDoC system (Figee et al., 2016). However, it is the first time that experts in this field endorse this formally through a consensus-based methodology. Furthermore, the recognition of compulsivity as a new transdiagnostic dimension may be useful in understanding the mechanisms involved not only in OCRDs, but also in some non-OCRDs that seem to exhibit compulsive behaviors in their clinical presentation (e.g. addictions and binge eating disorder) (Fontenelle et al., 2011). In a previous Delphi review, experts in the field of addiction also suggested compulsivity, as well as habit and response inhibition, as underlying constructs thought to be dysfunctional in substance and behavioral addictions (Yucel et al., 2019).

Intriguingly, despite the transdiagnostic importance of compulsivity, agreement around its most suitable definition remains elusive (Luigjes and Denys, 2019). Behavioral characterizations tend to 
emphasize its observable aspects, such as 'actions which are repeated despite adverse consequences' (Grant et al., 2016), whereas phenomenological definitions focus on the subjective experience of people suffering from $\mathrm{OCD}$, for example, 'the inability not to perform an act, with a subjective feeling of loss of control vis-à-vis oneself' (Denys, 2014). In addition, the behavioral definition of compulsivity tends to concentrate on 'the negative consequences that make little or no sense within a particular context', while the phenomenological perspective emphasizes the 'lack of experienced freedom' (Luigjes and Denys, 2019). Both perspectives are valid which makes it difficult to establish which approach is more appropriate. For the specific objectives of the RDoC, the observable approach may be more readily translatable to animal models. However, a first person perspective is equally important for clinicians to understand their patients' experiences (Luigjes and Denys, 2019). Clinically, compulsivity is experienced as 'the feeling that one must resist' the symptom (Burgy, 2019).

There is another potential problem with the concept of compulsivity. In contrast to the three identified RDoC constructs, which reflect well studied brain functions or abilities, compulsivity may be more closely related to a pathological (or clinical) feature per se, i.e., the ultimate result of a disturbed underlying neurobiological system. In this sense, arguing that compulsivity is a feature shared by OCRDs may not really advance our basic research question and can be considered somewhat tautological. Nevertheless, the fact that experts agreed compulsivity was a transdiagnostic construct highlights the continued need to understand how dysfunctional neurobiological systems interact with other variables in order to generate symptoms shared by all OCRDs. By doing so, it implicitly calls into question environmental risk factors, which are not mentioned in the current RDoC matrix, but may shape underlying compulsivity to determine specific OCRDs phenotypes.

As in our previous Delphi study on addiction (Yucel et al., 2019), experts were asked which stage they believed each RDoC construct played a significant role, either in the vulnerability to or chronicity of OCRDs. While addiction experts previously suggested that habit and compulsivity play a greater role in later stages of addiction processes (Yucel et al., 2019), no construct identified as relevant for OCRD stood out as particularly relevant to early or later stages of OCRDs. Experts therefore considered OCRD systems to be stably impaired from the outset, with no change in the underlying dysfunctional systems as illnesses progress. Indeed, the fact that most OCRDs have a particular course, with early and insidious onset, may compromise an accurate identification of stages of illness and make it difficult to distinguish vulnerability from chronicity in OCRDs. Nonetheless, staging systems for OCD likely represent a step forward to dissect these phases biologically (Fontenelle and Yucel, 2019).

The endorsement of positive valence, cognitive control and compulsivity as relevant to the pathophysiology of OCRDs is consistent with the traditional conceptual/theoretical models that posit emotion, cognition and behavior are key ingredients to the phenotypical expression of OCD (Oberbeck et al., 2013), the theoretical backbone of OCRDs. The specific involvement of habit formation, response selection/inhibition and performance monitoring, and compulsivity constructs dovetails with the bulk of data from brain imaging studies in OCRDs that implicate CSTC, fronto-limbic and fronto-parietal circuits (Nakao et al., 2014). What remains unclear is how these constructs, and their underlying networks, may be related to personalized treatment and prevention. There is some suggestion that emotion and cognitive networks, rather than the classical orbitofronto-striatal loop, might be related to differential response to treatment (Nakao et al., 2014). 
To clarify these and other issues, future research protocols should seek to examine larger numbers of subjects with different 'candidate' OCRDs assessed for multiple 'units of analysis' (such as genes, molecules, cells, circuits, physiological markers, etc.) that underpin the key RDoC constructs and treat them with different approaches. These initiatives should verify which OCRDs share dysfunctions in the four constructs reported above and reflect expressions of a common underlying vulnerability that may be remediated by similar kinds of cognitive-phenotype targeted, transdiagnostic treatments. Another area for future investigation would be to determine what happens to the dysfunction in these constructs (e.g. habit) over time, and over specific stages of illness. To answer this question, it would be interesting to follow the responses of an epidemiological sample of people with, or at risk of, OCRDs to specific instruments (Piquet-Pessoa et al., 2019) or to cognitive tasks (e.g. outcome devaluation procedures (Gillan et al., 2011, 2014)), from early neurodevelopmental periods (childhood or adolescence) through to adult years.

Our study has some limitations. First, despite including a reasonable number of experts in OCRDs and receiving almost no declinations, some prominent researchers did not respond to our invitations to engage in the study. Second, one could argue that experts were selected for sharing their opinions on OCRDs from the outset, thus implicating in some sort of sampling bias. Although we cannot exclude the latter possibility, we attempted to select an eclectic group of participants that had a reasonable publication record, were members of editorial boards of specialized Journals, and were from different fields (psychiatrists, psychologists and neuroscientists), and working settings (clinical practice vs research). Finally, as we were interested in what OCRDs have in common rather than in their specificities, no comparisons between different OCRDs and their underlying constructs were performed. Asking experts to consider which constructs were specific to each OCRDs was beyond the scope of the present study, and was considered unfeasible for time reasons.

In this Delphi study, experts agreed that three RDoC and one additional construct are central to understanding the pathophysiology of OCRDs, namely habit, response selection/inhibition, performance monitoring and compulsivity. In addition to putatively cutting across OCRDs, these constructs may also have potential implications for clinical practice in the future, particularly in relation to the diagnosis and therapeutic management of OCRDs. The consensus obtained here may help to clarify the biological links between conditions that, for a long time, have been known to share many clinical overlaps. It also provides preliminary guidance to future research, allowing an initial step toward a more collaborative agenda between clinicians and neuroscientists that may eventually enable the refinement of OCRDs into a more homogeneous group.

\section{Acknowledgements}

L.F.F. has received grants from Conselho Nacional de Desenvolvimento Científico e Tecnológico (\# 308237/2014-5), Fundação Carlos Chagas Filho de Amparo à Pesquisa do Estado do Rio de Janeiro (\#E 26/203.052/2017), the D'Or Institute of Research and Education (no grant number) and the David Winston Turner Endowment Fund (no grant number). E.O. has no acknowledgments. M.E.M.-d.-O. has no acknowledgments. J.S.A. has no acknowledgments. M.A. has no acknowledgments. D.C. has no acknowledgments. A.C. has no acknowledgments. D.D. has no acknowledgments. Y.F. has no acknowledgments. M.F. has no acknowledgments. B.J.H. has no acknowledgments. M.H. has no acknowledgments. J.S.K. has no acknowledgments. A.K. has no acknowledgments. L.L. has no 
acknowledgments. C.L. has no acknowledgments. D.M. has no acknowledgments. D.M.-C. has no acknowledgments. D.M. has no acknowledgments. E.C.M. has no acknowledgments. S.M.-Z. has no acknowledgments. S.M. has no acknowledgments. G.N. has no acknowledgments. K.O. has no acknowledgments. S.P. has no acknowledgments. C.P. has no acknowledgments. S.R. has no acknowledgments. P.R. has no acknowledgments. J.-Y.R. has no acknowledgments. R.G.S. has received grants from Conselho Nacional de Desenvolvimento Científico e Tecnológico (\#307742/2012-1). C.S.-M. is supported by a 'Miguel Servet' contract from the Carlos III Health Institute (CPII16/00048). V.S. has no acknowledgments. D.J. has no acknowledgments. G.S. has no acknowledgments. E.S. received research support from the National Institutes of Health (NIH), the Red Cross, the Greater Houston Community Foundation, the Rebuild Texas Foundation, Mental Health America-Houston and the Texas Education Coordinating Board. S.T. has no acknowledgments. O.A.v.H. has no acknowledgments. D.V. has no acknowledgments. D.W.W. has no acknowledgments. A.V.-G. has received a CDF Fellowship from the Australian Medical Research Future Fund (MRF1141214). M.Y. has received funding from Monash University, and Australian Government funding bodies such as the National Health and Medical Research Council (NHMO; including Fellowship \#APP1117188), the Australian Research Council (ARC) and the Department of Industry, Innovation and Science. He has also received philanthropic donations from the David Winston Turner Endowment Fund, as well as payment from law firms in relation to court and/or expert witness reports.

\section{Declaration of conflicting interests}

L.F.F. has no disclosures. E.O. has no disclosures. M.E.M.-d.-O. has no disclosures. J.S.A. has no disclosures. M.A. has no disclosures. D.C. has no disclosures. A.C. has no disclosures. D.D. has no disclosures. Y.F. has no disclosures. M.F. has no disclosures. B.J.H. has no disclosures. M.H. has no disclosures. J.S.K. has no disclosures. A.K. has no disclosures. L.L. has no disclosures. C.L. has no disclosures. D.M. has no disclosures. D.M.-C. receives royalties from Wolters Kluwer Health and Elsevier, all outside the submitted work. D.M. has no disclosures. E.C.M. has no disclosures. S.M.-Z. has no disclosures. S.M. has no disclosures. G.N. has no disclosures. K.O. has no disclosures. S.P. has no disclosures. C.P. has no disclosures. S.R. has no disclosures. P.R. has no disclosures. J.-Y.R. has no disclosures. R.S. has no disclosures. C.S.-M. has no disclosures. V.S. has no disclosures. D.J.S. has no disclosures. G.S. has no disclosures. E.S. served as a consultant for Levo Pharmaceuticals. He has received book royalties from Elsevier, Lawrence Erlbaum, Springer, Jessica Kingsley and the American Psychological Association. S.T. has no disclosures. O.A.v.d.H. has no disclosures. D.V. has no disclosures. D.W.W. has no disclosures. A.V.-G. has no disclosures. M.Y. has no disclosures.

\section{Funding}

The authors disclosed receipt of the following financial support for the research, authorship and/or publication of this article: This study was supported by (1) Conselho Nacional de Desenvolvimento Científico e Tecnológico (CNPq): 308237/2014-5; (2) Fundação Carlos Chagas Filho de Amparo à Pesquisa do Estado do Rio de Janeiro (FAPERJ): E 26/203.052/2017; (3) The D'Or Institute of Research and Education (IDOR): no grant number; (4) David Winston Turner Endowment Fund (DWTEF): no grant number; (5) Conselho Nacional de Desenvolvimento Científico e Tecnológico (CNPq): 307742/2012-1; (6) Carlos III Health Institute: CPII16/00048; (7) Australian Medical Research Future Fund: MRF1141214; (8) National Institutes of Health (NIH): no grant number; (9) Red Cross: no grant number; 
(10) Greater Houston Community Foundation: no grant number; (11) Rebuild Texas Foundation: no grant number; (12) Mental Health America-Houston: no grant number; (13) Texas Education Coordinating Board: no grant number; (14) National Health and Medical Research Council (NHMRC): APP1117188; (15) Australian Research Council (ARC): no grant number; and (16) Department of Industry, Innovation and Science: no grant number.

\section{References}

Abramovitch, A, Cooperman, A (2015) The cognitive neuropsychology of obsessive-compulsive disorder: A critical review. Journal of Obsessive-Compulsive and Related Disorders 5: 24-36.

Akins, RB, Tolson, H, Cole, BR (2005) Stability of response characteristics of a Delphi panel: Application of bootstrap data expansion. BMC Medical Research Methodology 5: 37.

Andersen, NB, Bech, $P$ (1981) Characteristics of negative reinforcement in obsessive-compulsive behaviors. Scandinavian Journal of Behaviour Therapy 10: 21-29.

APA (2013) Diagnostic and Statistical Manual of Mental Disorders. Washington, DC: American Psychiatric Publishing.

Bolger, F, Wright, G (2011) Improving the Delphi process: Lessons from social psychological research. Technological Forecasting and Social Change 78: 1500-1513.

Braun, V, Clarke, V (2006) Using thematic analysis in psychology. Qualitative Research in Psychology 3: 77-101.

Brooks, SJ, Lochner, C, Shoptaw, S, et al. (2017) Using the research domain criteria (RDoC) to conceptualize impulsivity and compulsivity in relation to addiction. Progress in Brain Research 235: 177-218.

Burgy, M (2019) Phenomenology of obsessive-compulsive disorder: A methodologically structured overview. Psychopathology 52: 174-183.

Carrasco, M, Hong, C, Nienhuis, JK, et al. (2013) Increased error-related brain activity in youth with obsessive-compulsive disorder and other anxiety disorders. Neuroscience Letters 541: 214218.

Chamberlain, SR, Fineberg, NA, Menzies, LA, et al. (2007) Impaired cognitive flexibility and motor inhibition in unaffected first-degree relatives of patients with obsessive-compulsive disorder. The American Journal of Psychiatry 164: 335-338.

Chamberlain, SR, Menzies, L, Hampshire, A, et al. (2008) Orbitofrontal dysfunction in patients with obsessive-compulsive disorder and their unaffected relatives. Science 321: 421-422.

Cuzen, NL, Stein, DJ, Lochner, C, et al. (2014) Comorbidity of obsessive-compulsive disorder and substance use disorder: A new heuristic. Human Psychopharmacology: Clinical \& Experimental 29: 89-93.

de Vries, FE, de Wit, SJ, Cath, DC, et al. (2014) Compensatory frontoparietal activity during working memory: An endophenotype of obsessive-compulsive disorder. Biological Psychiatry 76: 878887.

de Wit, SJ, de Vries, FE, van der Werf, YD, et al. (2012) Presupplementary motor area hyperactivity during response inhibition: A candidate endophenotype of obsessive-compulsive disorder. The American Journal of Psychiatry 169: 1100-1108.

Denys, D (2011) Obsessionality \& compulsivity: A phenomenology of obsessive-compulsive disorder. Philosophy, Ethics, and Humanities in Medicine 6: 3.

Denys, D (2014) Compulsivity and free will. CNS Spectrums 19: 8-9. 
Diamond, IR, Grant, RC, Feldman, BM, et al. (2014) Defining consensus: A systematic review recommends methodologic criteria for reporting of Delphi studies. Journal of Clinical Epidemiology 67: 401-409.

Endrass, T, Ullsperger, M (2014) Specificity of performance monitoring changes in obsessivecompulsive disorder. Neuroscience \& Biobehavioral Reviews 46: 124-138.

Ferreira, GM, Yucel, M, Dawson, A, et al. (2017) Investigating the role of anticipatory reward and habit strength in obsessive-compulsive disorder. CNS Spectrums 22: 295-304.

Figee, M, Pattij, T, Willuhn, I, et al. (2016) Compulsivity in obsessive-compulsive disorder and addictions. European Neuropsychopharmacology 26: 856-868.

Fineberg, NA, Saxena, S, Zohar, J, et al. (2010) Obsessive-compulsive disorder: Boundary issues. In: Hollander, E, Zohar, J, Sirovatka, PJ, et al. (eds) Obsessive-Compulsive Spectrum Disorders: Refining the Research Agenda for DSM-V. Arlington, VA: American Psychiatric Publishing, pp. $1-32$.

Fontenelle, LF, Yucel, M (2019) A clinical staging model for obsessive-compulsive disorder: Is it ready for prime time? EclinicalMedicine 7: 65-72.

Fontenelle, LF, Mendlowicz, MV, Versiani, M (2005) Impulse control disorders in patients with obsessive-compulsive disorder. Psychiatry and Clinical Neurosciences 59: 30-37.

Fontenelle, LF, Oostermeijer, S, Harrison, BJ, et al. (2011) Obsessive-compulsive disorder, impulse control disorders and drug addiction: Common features and potential treatments. Drugs 71: 827-840.

Gillan, CM, Kosinski, M, Whelan, R, et al. (2016) Characterizing a psychiatric symptom dimension related to deficits in goal-directed control. Elife 5: e11305.

Gillan, CM, Morein-Zamir, S, Urcelay, GP, et al. (2014) Enhanced avoidance habits in obsessivecompulsive disorder. Biological Psychiatry 75: 631-638.

Gillan, CM, Papmeyer, M, Morein-Zamir, S, et al. (2011) Disruption in the balance between goaldirected behavior and habit learning in obsessive-compulsive disorder. The American Journal of Psychiatry 168: 718-726.

Gottesman, II, Gould, TD (2003) The endophenotype concept in psychiatry: Etymology and strategic intentions. The American Journal of Psychiatry 160: 636-645.

Grant, JE, Fineberg, NVAN, Ameringen, M, et al. (2016) New treatment models for compulsive disorders. European Neuropsychopharmacology 26: 877-884.

Guzys, D, Dickson-Swift, V, Kenny, A, et al. (2015) Gadamerian philosophical hermeneutics as a useful methodological framework for the Delphi technique. International Journal of Qualitative Studies on Health and Well-Being 10: 26291.

Hasson, F, Keeney, S, Mckenna, H (2000) Research guidelines for the Delphi survey technique. Journal of Advanced Nursing 32: 1008-1015.

Jorm, AF (2015) Using the Delphi expert consensus method in mental health research. Australian and New Zealand Journal of Psychiatry 49: 887-897.

Linstone, HA, Turoff, M (1975) The Delphi Method: Techniques and Applications (Advanced Book Program). Reading, MA: Addison-Wesley.

Luigjes, J, Denys, D (2019) The philosophy of compulsive disorders: Compulsivity and free will. In: Fontenelle, LF, Yücel, M (eds) A Transdiagnostic Approach to Obsessions, Compulsions and Related Phenomena. Cambridge: Cambridge University Press, pp. 14-18.

Marras, A, Fineberg, N, Pallanti, S (2016) Obsessive compulsive and related disorders: Comparing DSM-5 and ICD-11. CNS Spectrums 21: 324-333. 
Mataix-Cols, D, Fernandez De, La, Cruz, L, Nordsletten, AE, et al. (2016) Towards an international expert consensus for defining treatment response, remission, recovery and relapse in obsessive-compulsive disorder. World Psychiatry 15: 80-81.

Nakao, T, Okada, K, Kanba, S (2014) Neurobiological model of obsessive-compulsive disorder: Evidence from recent neuropsychological and neuroimaging findings. Psychiatry and Clinical Neurosciences 68: 587-605.

NIMH (2017) Research domain criteria (RDoC). Available at: www.nimh.nih.gov/researchpriorities/rdoc/index.shtml (accessed 26 January 2017).

Oberbeck, A, Stengler, K, Steinberg, H (2013) [On the history of obsessive compulsive disorders: Their place in the nosological classifications up to the beginning of the 20th century]. Fortschritte der Neurologie Psychiatrie 81: 706-714.

Okoli, C, Pawlowski, SD (2004) The Delphi method as a research tool: An example, design considerations and applications. Information \& Management 42: 15-29.

Piquet-Pessoa, M, Chamberlain, SR, LEE, RSC, et al. (2019) A study on the correlates of habit-, reward-, and fear-related motivations in alcohol use disorder. CNS Spectrums 24: 597-604.

Pitman, RK (1987) A cybernetic model of obsessive-compulsive psychopathology. Comprehensive Psychiatry 28: 334-43.

Rauch, SL, Savage, CR, Alpert, NM, et al. (1997) Probing striatal function in obsessive-compulsive disorder: A PET study of implicit sequence learning. The Journal of Neuropsychiatry and Clinical Neurosciences 9: 568-573.

Riesel, A (2019) The erring brain: Error-related negativity as an endophenotype for OCD-A review and meta-analysis. Psychophysiology 56: e13348.

Riesel, A, Goldhahn, S, Kathmann, N (2017) Hyperactive performance monitoring as a transdiagnostic marker: Results from health anxiety in comparison to obsessive-compulsive disorder. Neuropsychologia 96: 1-8.

Riesel, A, Kathmann, N, Endrass, T (2014) Overactive performance monitoring in obsessivecompulsive disorder is independent of symptom expression. European Archives of Psychiatry and Clinical Neuroscience 264: 707-717.

Scheibe, M, Skutsch, M, Schofer, J (1975) Experiments in Delphi methodology. In: Linstone, HA, Turoff, M (eds) The Delphi Method: Techniques and Applications (Advanced Book Program). Reading, MA: Addison-Wesley, pp. 262-287.

Shaw, P, Sharp, W, Sudre, G, et al. (2015) Subcortical and cortical morphological anomalies as an endophenotype in obsessive-compulsive disorder. Molecular Psychiatry 20: 224-231.

Smith, KS, Graybiel, AM (2016) Habit formation. Dialogues in Clinical Neurosciences 18: 33-43.

Stein, DJ, Kogan, CS, Atmaca, M, et al. (2016) The classification of obsessive-compulsive and related disorders in the ICD-11. Journal of Affective Disorders 190: 663-674.

Sumsion, T (1998) The Delphi Technique: An Adaptive Research Tool. British Journal of Occupational Therapy 61: 153-156.

Tiego, J, Oostermeijer, S, Prochazkova, L, et al. (2019) Overlapping dimensional phenotypes of impulsivity and compulsivity explain co-occurrence of addictive and related behaviors. CNS Spectrums 24: 426-440.

Vaghi, MM, Hampshire, A, Fineberg, NA, et al. (2017) Hypoactivation and dysconnectivity of a frontostriatal circuit during goal-directed planning as an endophenotype for obsessivecompulsive disorder. Biological Psychiatry: Cognitive Neuroscience and Neuroimaging 2: 655663. 
Weinberg, A, Kotov, R, Proudfit, GH (2015) Neural indicators of error processing in generalized anxiety disorder, obsessive-compulsive disorder, and major depressive disorder. Journal of Abnormal Psychology 124: 172-185.

Yucel, M, Oldenhof, E, Ahmed, SH, et al. (2019) A transdiagnostic dimensional approach towards a neuropsychological assessment for addiction: An international Delphi consensus study. Addiction 114: 1095-1119. 